There is an extensive review of gastric freezing for the treatment of gastroduodenal ulceration. De Bakey in a footnote of critical comment considers it is unfortunate that it has been so widely used before it had been thoroughly evaluated and technically mastered, and believes it is doubtful value and that its place will be limited.

In this issue there is a new chapter on Transplantation and Artificial Organs.

The Year Book offers stimulating reading and Surgeons will find much of interest.

Medicine in Britain-A Guide for Overseas Doctors C. Allan Birch. Pp. xii +316 , illustrated. London: Balliére, Tindall and Cassell. 1966. $35 s$

Dr. Allan Birch has packed a remarkable amount of information into this book: there are sections on the National Health Service and on British medical practice and one giving General Information. There are 70 pages containing useful advice in Medicine, Paediatrics, Surgery, Obstetrics and Gynaecology contributed by himself and three colleagues and there is a final Historical Section. The material is compressed for the sake of brevity and the result is a book to be dipped into rather than read through. It will need regular revision if it is to keep abreast of the changing scene in medical practice in this country and information about the Commonwealth Scholarship and other schemes will be of great importance to readers.

This book will be very valuable to overseas graduates whilst graduates of British universities will find in it a source book for a great deal of varied information which they might have difficulty in tracing otherwise. It should find a place in all hospital libraries.

The Pediatric Patient 1965.

Edited by S. R. Gustafson and D. B. Coursin. Pp. 216, illustrated. Philadelphia and Montreal: J. B. Lippincott. London: Pitman Medical. 1965. $50 \mathrm{~s}$.

This is the third annual edition of this book. It has continued to increase in size and scope and at the same time the quality of production has improved. The Authors' stated object is to acquaint the "practitioner in pediatrics" with some of the advances in medicine relevant to his subject and this they do by means of short but well written reviews of recent literature on selected topics. They contrive to be more up-to-date than most textbooks, but are not too heavily burdened with references.

The subject matter is wide in scope and this year includes sections on 'The New Immunology', allergic disease, the newborn, new syndromes, vision and adolescence. The new text concludes, as before, with a "miscellany in brief". The result is a pleasing and stimulating commentary on numerous aspects of the paediatric world, and it must surely be one of the few medical publications that actually invites criticism from its readers and requests suggestions for topics to be included in subsequent issues.

Although there is no exact British equivalent of the American "practising pediatrician" for whom the work is intended, nevertheless, all those who are involved in the care of children in this country will enjoy this publication.
The Practitioner's Illustrated Dermatology

Howard T. Behrman and Theodore A. Labowz Pp. $x+189$, illustrated. New York and London: $:$ Grune and Stratton. 1965. \$9.75.

There has been a spate of new books on dermatology for the practitioner in recent years. Fortunately they differ greatly from each other and the intending buyer has a good choice of size, price $\frac{5}{0}$ style, and emphasis. This new book makes no bones about what it intends to do. Its object? is to be as helpful as possible clinically and to omit all theoretical material. It is simple, straight forward, and completely dogmatic and it succeeds $s^{\circ}$ in what it attempts. The commonest skin disorders are taken in alphabetical order and their most important synonyms are given. The left hand page $\vec{\omega}$ is given to clear, bright, colour photographs witho the text on the right. Each disorder is describedo clearly but very briefly and the treatment is givern fairly fully under the headings Internal and External: The last section of the book is a detailed formulary which contains a practical mixture of official remedies and American proprietory preparations. Finally there is a satisfactory index. The book is well produced with large type on good paper. Thew colour photographs are mostly well chosen and well reproduced. It is easy to disagree with somes of the details, and it must always be so with this kind of dogmatic and somewhat oversimplified text 3 Thus the dietetic restrictions demanded in suffererso from acne vulgaris seem to be excessive. These disagreements are unimportant and merely reflecte differences in practice among dermatologists. THe only serious adverse criticism is the inadequacy of the treatment of chronic leg ulcers. For those wo do not mind the price, this book is recommended

\section{Psychiatric Hospital Care}

A Symposium edited by Hugh Freeman. Pp. $301 \stackrel{\bar{\partial}}{3}$ London: Bailliere, Tindall \& Cassell. 1965. 50s? This book contains 32 articles given by Consultant0 Psychiatrists at a Symposium held at the Middlesex Hospital in January, 1964. The subject matter includes5 Mental Hospital Administration, the establishment of "Therapeutic Communities", Rehabilitation, Out-3 patient Departments, Day' Hospitals, PsychiatricPsychogeriatrics.

The Symposium has attracted many of the pioneerso related to the various subjects and much of the material has been the subject of previous publications? The articles are mainly of a high standard and the writing is often pungent and authoritative. There is some overlap of material discussed and oocasionallyos authors have taken opposite view points but this in no way detracts from the value of the book. In discussing the role of admission units one authorw takes the view that a unit should cater for all typeso of patients and feels "There is no evidence as fat as we are aware that one type of patient, whethere young or old, has had a deleterious effect upon anyes other patient"; while other authors endeavour to create group cohesion upon their wards by carefulo classification of patients.

Some 'old guard' attitudes still prevail, e.g. In Chapter 6 discussing the Team System "The recogni $\frac{\text { P }}{\mathbb{D}}$ 